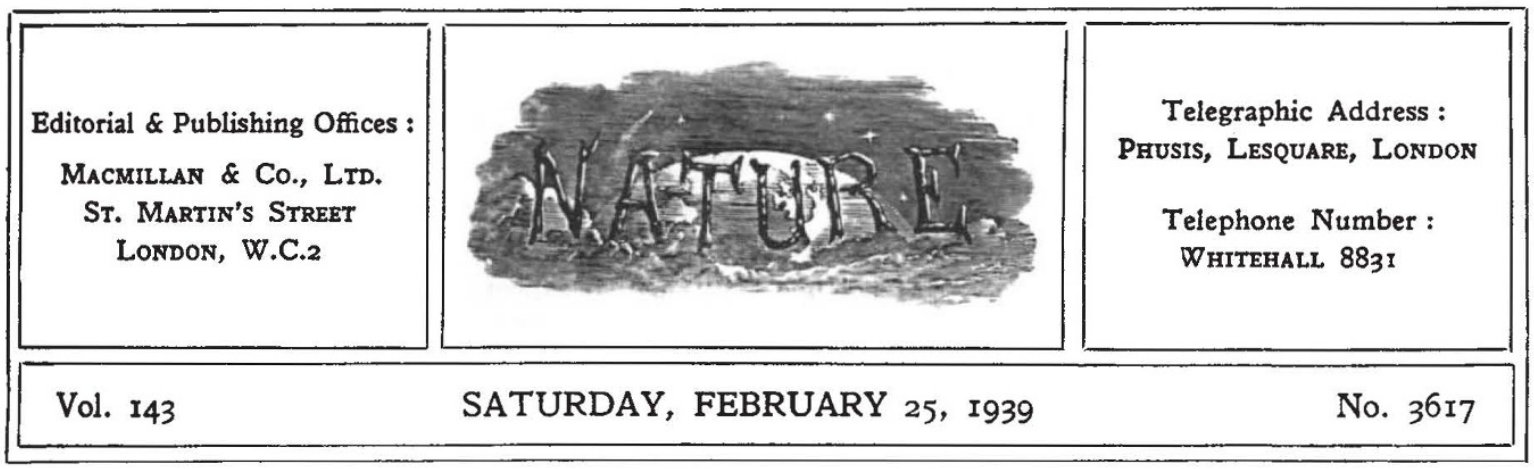

\title{
Science and Democracy
}

A MANIFESTO on the relation of science to present developments in the international political situation has been issued on behalf of American men of science by a committee, of which Prof. Franz Boas of Columbia University, the doyen of American anthropologists, is the protagonist. It is a document which is no less remarkable for the extent and character of the support it receives, in view of conditions in the United States, than for its argument. It is signed by 1,284 scientific workers, including three Nobel Prize winners, Prof. Harold C. Urey of Columbia University, Prof. R. A. Millikan of the California Institute of Technology, and Dr. Irving Langmuir of the General Electric Company, Schenectady, N.Y. The signatories are drawn from a hundred and sixty-seven universities and research institutes, and include eighty-five college presidents, deans, and directors of industrial laboratories and experimental stations; sixty-four are members of the National Academy of Sciences.

The signatories call upon their colleagues to participate actively in the defence of democracy as the sole means of preserving intellectual freedom and insuring scientific progress. It is perhaps unnecessary to recall that, as the oldest and the greatest of existing democracies, the people of the United States cherish as their proudest and dearest political possessions the right of free thought, the right of free speech, and the rule of the majority. These are for them, as they have been for all free peoples (at least of modern times) the fundamental conditions of truth and justice, and as such the basis of free and democratic institutions. The aim of the manifesto is, broadly speaking, to demonstrate, and to urge upon all scientific workers the duty of showing to the people of the United States that the development of political theory and practice in the totalitarian States cuts at the root of these principles, and at the same time at the freedom of all mankind, as well as endangers the possibility of the advancement of man's wellbeing through the ministrations of science.

In demonstrating the relation of science to freedom of thought and speech under democratic institutions, the manifesto takes its stand on the recent resolution of the American Association for the Advancement of Science. "Science", it was there said, "is wholly independent of national boundaries and races and creeds and can flourish only when there is peace and intellectual freedom." "If science", the manifesto goes on to say, "is to continue to advance and spread more abundantly its benefits to all mankind, then the man of science has a moral obligation to fulfil. He must educate the people against the acceptance of all false and unscientific doctrines which appear before them in the guise of science, regardless of their origin."

Further, the Fascist position towards science is publicly condemned. It is shown to have violated both truth and justice in the most profound sense by the imposition of scientific theories and doctrines which have been demonstrated time and again to be false, and by debarring a section of the population, Jews or 'non-Aryans', from intellectual and scientific activity; while the "thousands of teachers and scientists who have been exiled ... . bear testimony to the incompatibility of Fascism and science". The manifesto in this connexion goes even further and regards "the attack on freedom of thought in one sphere, even as nonpolitical a sphere as theoretical physics, as in effect an attack on democracy itself. When men like James Franck, Albert Einstein or Thomas Mann may no longer continue their work, whether the reason is race, creed, or belief, all mankind suffers the 
loss"; and it concludes, "If we American scientists wish to avoid a similar fate, if we wish to see the world continue to progress and prosper, we must bend our efforts to that end now."

The action of American men of science in issuing this manifesto on the relation of development in the international situation to the progress of science has fallen at a singularly opportune moment ; and its implications will not escape the notice of their colleagues in the countries of Europe. Unquestionably it has been to the advantage of the intellectual advancement of the world at large that, while in the political sphere the United States of America has held fast to isolation as a corollary of the Monroe Doctrine-a policy now for the second time within the present century under public consideration in view of danger to democratic institutions-that isolation has not been a characteristic of this great people in matters of the spirit, more especially in the development of the arts and in science. By free exchange and interchange of ideas and personnel, the New World has co-operated with the Old to their mutual benefit; while the recent approach of the American Association for the Advancement of Science to the British Association, for the promotion of joint consideration and discussion of problems of scientific import and socio-economic application, opens up further prospects of an accelerated movement towards world unity in attack on those broader questions in which science touches the interests and well-being of mankind as a whole. Notwithstanding differences in social conditions between the United States and the countries of the Old World, which would militate against either the utility, or perhaps even the possibility, of like action in the very different circumstances prevailing in the European democracies, nevertheless the pronouncement of American men of science inculcates a principle in its statement of the relation of scientific progress and democratic institutions, which may well be laid to heart ; and it is of no less importance that once more it has demonstrated in practical form the essential solidarity of the world of science.

\section{The Census and the Distribution of Population}

$\mathrm{E}$ VERY civilized community needs a full and accurate knowledge of its human resources; and bence the census has developed far beyond its primary function of merely numbering the people. It has become a periodic stocktaking; and among other aims it should provide precise and full information about the distribution of the people within a country.

Every person is counted at the place in which he, or she, is at the date of the census. This gives the first facts of the distribution, what is called the de facto population of each census district and of the country. In the past this has been considered sufficient, provided that the actual censua could be carried out within a very short time, so short that no appreciable movements took place during the count. Up to 1921 , it was the only distribution directly recorded by the census in Great Britain. But in that year the count was made in June, instead of in April as usual; and the holiday movements which had then begun caused serious uncertainties in the results as compared with those of other censuses and with intercensal estimates. Hence in 1931 there was introduced a question requiring each person to state his usual, or legal, place of residence.
This made it possible to count the regular inhabitants of each district, and so to measure the de jure population, by excluding visitors and including temporary absentees, a second stage in an accurate measure of distribution. The difference between the de facto and the de jure populations may at some places and times be considerable, especially in a holiday resort such as Blackpool ; and it is obviously necessary to know the numbers of the resident population for many purposes of administration. The counting of the de jure population has always been the aim of censuses taken to determine electoral constituencies, as in the United States of America; it is surprising that it did not come earlier in Great Britain.

The requirement that each person shall state his place of birth enables the census to obtain some information regarding the origins and migrations of the people it enumerates. It is regret. table that the separation of Eire from the United Kingdom in 1922 has been allowed to interrupt the continuity of the records under this head. This can be avoided for the future if under 'birthplace' in the schedule we write 'British Isles' in place of 'United Kingdom'; and so obtain records 